\title{
Secure Attachment Conceptualizations: \\ The Influence of General and Specific Relational Models on Conflict Beliefs and Conflict Resolution Styles ${ }^{1}$
}

\author{
Karin du Plessis, Dave Clarke, and Cheryl C. Woolley \\ Massey University, New Zealand
}

\begin{abstract}
Attachment theory focuses on the cognitive models that underlie our interactions with attachment figures. Global or generalized mental models are thought to develop on the basis of attachment models with parents and might form the initial basis of internal working models in novel relationships. However, as discrepant information presents itself in a new relationship, it is thought that specific relational models develop. When conflict arises it can threaten the attachment bonds of the relationship. An Internet survey of 134 individuals in couple relationships was conducted to test the influence of secure parental and partner attachment conceptualizations on romantic relationship variables (conflict beliefs and conflict resolution styles). Results indicated that for the most part relationship variables were influenced by current secure romantic attachment conceptualizations. Analyses also indicated differential gender results for positive problem solving in terms of secure parental and partner attachment. Secure parental attachment was also found to impact on the report of compliant behavior during conflict resolution. Lastly, the belief that arguing is threatening was found to be impacted by an interaction effect between parental and partner attachment. In general secure partner attachment was more predictive of conflict resolution behavior and conflict beliefs, than a global attachment model. However, it would appear that the global attachment model can be activated in the context of the current relationship under certain conditions. This research lends support to the notion that generalized and specific attachment representations impacts differently on close relationship functioning, and encourages a further mapping of relationship functions in this regard.
\end{abstract}

Keywords: attachment, attachment conceptualization, relational models, conflict beliefs, conflict resolution.

Over the past two decades attachment theory has become a driving theoretical perspective in research on adult romantic relationships. Initially developed by Bowlby (1969, $1973,1988)$ to explain parent-child bonds, attachment theory focus on the cognitive models that underlie our interactions with attachment figures. In infant attachment secure relationships are characterized by an infant's confidence that their primary caregiver will be available, helpful and comforting should a frightening situation arise (Bowlby, 1988).

\footnotetext{
${ }^{1}$ This research was based on the first author's doctoral dissertation at Massey University, New Zealand in partial fulfillment of the requirements for a doctoral degree - made possible by a Massey Doctoral Scholarship. Correspondence should be addressed to Dave Clarke, Department of Psychology, Massey University, Private Bag 102 904, NSMSC, Auckland, New Zealand; e-mail: d.clarke@massey.ac.nz
} 
Infants who have an anxious-ambivalent (preoccupied) relationship with their caregivers are unsure whether their caregivers will be responsive. As a result they make conflicted and often ineffective attempts to receive support from caregivers (Simpson \& Rholes, 1998). Infants who develop avoidant relationships with their caregivers have lost all confidence that the caregiver will be helpful, and as such do not seek support when they are distressed.

Hazan and Shaver (1987) developed a typology for adult romantic love analogous to Ainsworth's depictions of infant attachment (Ainsworth, Blehar, Waters, \& Wall, 1978). They distinguished between self-reported secure, avoidant and preoccupied attachment descriptions for adult relationships based on their beliefs that early relationships have an impact on adult relationships, and that the process of being involved in an intimate adult relationship shares similarities with infant-caregiver attachment (Bartholomew \& Shaver, 1998; Collins \& Read, 1994).

More recent research has indicated that attachment representations are relatively stable over time, but also remain open to change through new experiences (e.g., Crowell, Treboux, \& Waters, 2002). Furthermore, it has been theorized that there is a distinction between global and specific relational models of attachment (e.g., Collins \& Read, 1994; Crittenden, 1990). Global or generalized mental models are thought to develop on the basis of attachment models with parents and might form the initial basis of internal working models in novel relationships. However, as discrepant information presents itself in a new relationship, it is thought that specific relational models develop (Collins \& Read; Crittenden). More recent research has confirmed the distinction between global and specific relational models, and that global models shape specific models over time (Pierce \& Lydon, 2001). Overall, Fletcher and Friesen (2003) also found support for a model which indicates that specific relational models (e.g., attachment to your partner) function under relationship domains (e.g., romantic domain) which in turn function under a global relational model. Relationship specific mental models have also been found to be more closely associated with relationship specific outcomes, such as relationship satisfaction, than generalized models (Cozzarelli, Hoekstra, \& Bylsma, 2000).

Attachment and conflict

When conflict arises it can threaten the attachment bonds of the relationship. Additionally, from an attachment perspective conflict creates a dilemma: the person, who is generally sought out when one is distressed, now becomes a source of threat. In this sense conflict situations also present the ideal opportunity to study attachment styles that become more pronounced as a result of threatening situations (Bowlby, 1988). Various attachment styles have been found to be linked to specific behavior in the context of the relationship; for 
example, individuals with secure and preoccupied attachment styles display communicative behaviour that exhibit intimacy, whereas avoidants' style is characterized by withdrawal and detachment (Guerrero, 1996). Self-reported attachment classifications have furthermore been found to be a significant predictor of behavioural processes and outcomes, such as conflict resolution (e.g., Bippus \& Rollin, 2003).

Conflict resolution styles. Through interactions with the primary caregiver, the securely attached child learns that to maintain proximity, they should during conflict (which is inherently threatening to the attachment system) regulate their emotions so that they can remain calm to listen, negotiate and compromise during conflict resolution (Mikulincer, Gillath, \& Shaver, 2002). This then increases the likelihood that they will continue to view the primary caregiver as a safe haven and a secure base from which they can explore their environment (Mikulincer et al., 2002). In return their primary caregiver would also more than likely be securely attached and would be setting an example of this behaviour. Previous research has indicated that adults with secure global models of attachment use more positive and less negative behaviour in romantic relationships when contrasted with insecure adults (Creasy, 2002; Shi, 2003; Wampler, Shi, Nelson, \& Kimball, 2003). More specifically, Creasy found that the globalized attachment models of women predicted the use of positive behaviours in conflict situations, whereas the attachment models of men predicted the use of negative behaviours. Securely attached individuals are, according to Pistole (1989), more prone to using an integrative conflict strategy, and as a result also report higher relationship satisfaction.

Conflict beliefs. Securely attached people report less fighting and more effective arguing, whereas preoccupied individuals view conflict as an attachment threat and focus on re-establishing togetherness, which might in turn hamper effective problem solving (Pistole $\&$ Arricale, 2003). In terms of believing that arguing is beneficial, Pistole and Arricale found no differences among the various attachment styles of secure, preoccupied or avoidant individuals. However, securely attached individuals have been found to report less maladaptive attributions about partner behaviours than insecurely attached individuals (Sümer \& Cozzarelli, 2004). Individuals with a preoccupied or avoidant adult attachment style have also been found to endorse more relationship specific irrational beliefs than those with a secure attachment to their romantic partner (Stackert \& Bursik, 2003). In their research Pistole and Arricale found that avoidantly attached individuals view arguing as threatening to their attachment. Further research has indicated that preoccupied individuals are expected to believe that conflict would have negative consequences for their relationships (Campbell, Simpson, Boldry, \& Kashy, 2005). This is based on the notion that preoccupied individuals, having received inconsistent or deficient support from their primary caregivers, have developed low thresholds for perceiving threats to proximity maintenance, and would 
as a result be highly concerned with closeness (Simpson \& Rholes, 1994; Campbell et al., 2005)

Hypotheses

As suggested by previous findings (e.g., Creasy, 2002; Shi, 2003) secure partner attachment is expected to be positively correlated with positive problem solving, and negatively correlated with negative behaviours during conflict, including withdrawal, compliance and conflict engagement (hypothesis 1). Furthermore, secure partner attachment is expected to be positively correlated with a belief that arguing is beneficial, and negatively correlated with a belief that arguing is threatening (Pistole \& Arricale, 2003) (hypothesis 2).

In Treboux, Crowell and Waters' recent study (2004) they found that a secure generalized presentation (which they define as the attachment to the primary caregiver) was likely to be associated with a somewhat greater likelihood of having a secure conceptualisation of the current relationship. In line with this, Owens and her colleagues (1995) found that secure attachment style with the primary caregiver correlated approximately 0.29 with a secure attachment style to the partner (Owens, Crowell, Pan, Treboux, O'Connor, \& Waters, 1995). It is thus expected that secure partner attachment and secure primary caregiver attachment will have a weak to moderate positive correlation (hypothesis 3).

Although a large amount of research has established connections between adult attachment styles and functioning in close relationships (e.g., Creasey, 2002), there has also been recognition that more research is needed to explore how childhood attachment models (or global models) have an ongoing impact on specific relational outcomes such as those in romantic relationships (Paley, Cox, Burchinal \& Payne, 1999; Pierce \& Lydon, 2001). The present study builds on some previous research by exploring secure primary caregiver and romantic partner attachment differences, and its influence on relationship specific outcomes - specifically conflict beliefs and conflict resolution styles. Based on previous research findings (e.g., Cozzarelli et al. 2000) it is expected that partner-specific models of attachment would have a greater impact on relationship-specific variables, such as conflict resolution styles and conflict beliefs, than a global model of attachment (hypothesis 4)

\section{Method}

\section{Participants}

The 134 individual participants (92 females, 42 males) were recruited through media advertisements in the Auckland region. The study focused on the responses of one partner 
in a heterosexual relationship to the Internet questionnaire. The median age for the sample was 37 years $(M=38, S D=11.17$ years), with a range of 19 to 70 years. Participants were required to currently cohabitate in a heterosexual relationship for at least 6 months, and the sample had a median an cohabitation length of 7 years ( $M=134$ months, $S D=128$ months). Most participants indicated their mother as primary caregiver (86.6\%), whereas some indicated their father (8.4\%), or other, for example nanny/governess. The majority of the sample was of New Zealand European descent (64.2\%), with some Maori and Pacific Islander participants (8.9\%), and Other participants totaling 26.9\% (e.g., Australian, South African, Indian, European, British, and American). Full time employed participants totaled 66.4\%, whereas $12.7 \%$ were employed part time, $9 \%$ were full time homemakers, and $8.2 \%$ were full time students (with $3.7 \%$ either retired or unemployed).

\section{Methodological considerations}

This study was presented to participants via the Internet. Fouladi, McCarthy and Moller (2002) conducted a study on emotional functioning and attachment in a sample of college students, and compared paper-and-pencil versions of the study with a web-based version. Despite subtle differences, they found mostly similarities between the two different modes of survey administration. An increasingly popular method of survey delivery (Peden \& Flashinski, 2004), online surveys have become a new tool for data collection from participants, that according to Krantz and Dalal (2000) go "well beyond using introductory psychology students, phone and mail surveys, and the exhausting effort of soliciting subjects from the community" (p. 36). Previous research has indicated that means and range on Likert-type responses were very similar for web-based and paper-and-pencil questionnaires (e.g., Kiesler \& Sproull, 1986; Mehta \& Sivadas, 1995; Smith \& Leigh, 1997). In addition, faster response times and fewer expenses for web-based surveys have also been reported (Krantz \& Dalal). All these factors together contributed to the decision to utilize this method of data collection in this study.

\section{Measures}

The participants completed the following measures: Parent and Partner Attachment Scale (Le Poire, Haynes, Driscoll, Driver, Wheelis, Hyde, et al., 1997), Conflict Resolution Style Inventory (Kurdek, 1994), and Feelings About Conflict Scale (Pistole \& Arricale, 2003).

Parent and Partner Attachment Scale. Participants completed a relationship attachment scale developed by Le Poire et al. (1997). This Parent and Partner Attachment Scale (PPAS) has been used in previous research (e.g., Le Poire, Shephard, \& Duggan, 1999), and features a 
7 -point Likert scale $(1=$ strongly disagree to $7=$ strongly agree). The secure subscales measure the individuals' current perception of secure childhood attachment, as well as their current perspectives of secure attachment to their romantic partner. The Secure Romantic subscale (12 items) included items such as (1) "I believe that my partner is capable of unconditional positive regard", and (2) "My partner is always there for me in times of crisis". Previous research (Le Poire et al., 1997; Le Poire et al., 1999) indicated reliability estimates ranging from .83 to .90 . The secure partner scale for the present sample had an alpha reliability estimate of .88 . The Secure Parental subscale asks 18 attachment-related questions about the primary caregiver, and included items such as (1) "When s/he left me, I felt confident that s/he would return", and (2) "My primary caregiver was always there for me in times of crisis". Previous research (Le Poire et al., 1997; Le Poire et al., 1999) indicated reliability estimates ranging from .93 to .94 . It had an alpha reliability coefficient of .95 in the current study.

Conflict Resolution Style Inventory. The Conflict Resolution Styles Inventory (CRSI) is a 16-item self-report questionnaire that measures the participant's frequency $(1=$ never to $5=$ always) of engaging in certain conflict resolution styles with their partner (Kurdek, 1994). The 16 items are divided into four categories of conflict resolution styles: Positive Problem Solving, Conflict Engagement, Withdrawal, and Compliance, and the scale is based on behavioural observations of conflict resolution by Gottman and Krokoff (1989). The CRSI have been linked to changes in relationship satisfaction (Gottman, 1994), has good concurrent-related and predictive criteria-related validity, and test-retest correlations spanning a 1-year period ranged from .46 to .83. (Kurdek, 1994). For the present study, alpha values ranged from .69 to .87 .

Conflict beliefs. The Feelings About Conflict Questionnaire (FACQ) that was recently developed by Pistole and Arricale (2003) was used to explore attachment-related beliefs to conflict. Participants were asked to indicate whether they agreed or disagreed with 33 statements regarding their intimate relationships by using a 7 -point Likert scale $(1=$ strongly disagree to 7 = strongly agree). The Arguing is Threatening subscale included items such as (1) "During conflict, I often have to defend myself"and (2) "Arguments with my partner make me feel like the relationship is threatened". Pistole and Arricale (2003) found that Arguing is Threatening had a reliability of .90, and in the current study this subscale had an alpha reliability or .92. The Arguing is Beneficial subscale included items such as (1) "Our conflicts seem to bring us closer together" and (2) "I understand my partner better after a disagreement". This scale had a reliability of .87 in the current study comparable to Pistole and Arricale's finding of .85 . 


\section{Results}

A Pearson product-moment correlation matrix including all the variables in this study is included in Table 1. As predicted (hypothesis 1) secure partner attachment was positively correlated with Positive Problem Solving $(r=.52)$, and negatively correlated with Conflict Engagement $(r=-.41)$, Withdrawal $(r=-.44)$ and Compliance $(r=-.31), p_{\mathrm{s}}<.01$. Secure partner attachment was also found to be positively correlated with a belief that Arguing is Beneficial $(r=.48, p<.01)$, and negatively correlated with a belief that Arguing is Threatening $(r=-.69, p<.01)$ (hypothesis 2$)$. In addition Secure Partner Attachment and Secure Parental Attachment were found to have weak positive correlation $(r=.22, p<.05)$, thus supporting hypothesis 3 .

Table 1

Correlations of Secure Partner and Parent Attachment, Conflict Resolution Styles and Conflict Beliefs $(N=134)$

\begin{tabular}{|c|c|c|c|c|c|c|c|c|}
\hline Variable & 1 & 2 & 3 & 4 & 5 & 6 & 7 & 8 \\
\hline 1. Secure Partner Attachment & - & & & & & & & \\
\hline Parental & $.22 *$ & - & & & & & & \\
\hline \multicolumn{9}{|l|}{ Attachment } \\
\hline Conflict Resolution Styles & & & - & & & & & \\
\hline 3. Positive Problem Solving & $.52 * *$ & .10 & & & & & & \\
\hline 4. Conflict Engagement & $-.41 * *$ & -.07 & $-.48 * *$ & - & & & & \\
\hline 5. Withdrawal & $-.44 * *$ & -.16 & $-.46 * *$ & $.37 * *$ & - & & & \\
\hline 6. Compliance & $-.31 * *$ & $-.25 * *$ & $-.23 * *$ & .06 & $.43 * *$ & - & & \\
\hline Conflict Beliefs & & & & & & & - & \\
\hline 7. Arguing is threatening & $-.69 * *$ & $-.22 *$ & $-.58 * *$ & $.56 * *$ & $.48 * *$ & $.30 * *$ & & \\
\hline 8. Arguing is beneficial & $.48 * *$ & $.17^{*}$ & $.34 * *$ & -.12 & $-.34 * *$ & $-.33 * *$ & $-.43 * *$ & - \\
\hline Mean & 5.92 & 5.48 & 3.82 & 1.93 & 2.04 & 1.73 & 3.49 & 4.58 \\
\hline Standard Deviation & .92 & 1.25 & .77 & .75 & .74 & .59 & 1.13 & 1.01 \\
\hline
\end{tabular}

It was expected that partner-specific models of attachment would have a greater impact on relationship-specific variables, such as conflict resolution styles and conflict beliefs, than a global model of attachment (hypothesis 4). Hierarchical regression analyses were conducted to establish the extent to which global and specific secure attachment models are associated to relationship-specific variables, in particular conflict resolution styles (Table 2), and conflict beliefs (Table 3). In the first step of all of these regression analyses gender, secure partner attachment and secure parental attachment were entered as predictor variables, with interaction effects between these variables entered in the second 
step. It was deemed relevant to include gender, as previous research has found gender differences with regards to conflict behaviour and attachment models (e.g., Creasy, 2002). To minimize the effects of multicollinearity, it should be noted that secure parental and partner attachment were centered prior to the regression analyses (Aiken $\&$ West, 1991).

\section{Conflict resolution styles}

Positive problem solving. Table 2 shows the results of hierarchical regression analysis of the extent to which secure parent and partner attachment, as well as gender and their interaction effects contribute to each of the conflict resolution styles. Positive problem solving behaviour includes remaining calm to listen, negotiate and compromise during conflict. Gender, secure parental attachment, and secure partner attachment together accounted for $28 \%$ of the variance in positive problem solving at Step 1 . When examining the beta weights it becomes clear that secure partner attachment was the significant predictor at Step $1(=.52)$. The interaction effects between these variables explain another $5 \%$ of the variance in positive problem solving (Figures 1 and 2). With median splits of secure parental attachment (Figure 1) and secure partner attachment (Figure 2) on positive problem solving, gender differences become more evident. In terms of secure parental attachment (Figure 1), men who were highly securely attached to their parents were more likely than their highly securely attached female counterparts to display positive problem solving behaviour during conflict resolution. However, both men and women had low positive problem solving scores when their secure parental attachment was low. In terms of secure partner attachment (Figure 2 ), both men and women reported high positive problem solving behaviour when they were securely attached to their partners. However, if they were less securely attached women were less likely to using positive problem solving during conflict, than men.

Negative conflict resolution styles. Step 1 (gender, secure parental attachment and secure partner attachment) explained $17 \%$ of the variance in conflict engagement, $20 \%$ of the variance in withdrawal and $13 \%$ of the variance in compliance. No significant interaction effects became apparent for these negative conflict resolution styles. When examining the beta weights it becomes evident that secure partner attachment (partner-specific model) is contributing significantly to this model. Thus, having a secure partner attachment implied that individuals were less likely to engage in negative conflict resolution styles such as conflict engagement $(=-.41)$, withdrawal $(=-.42)$, and compliance $(=-.27)$. Having a secure parental attachment also meant that individuals were less likely to engage in compliant behaviour during conflict resolution $(=-.20)$.

These analyses suggest that both the general and specific models impact on conflict resolution behaviour in the current relationship. However, the significant beta values for the 
partner-specific model (as measured by secure partner attachment) were larger for all the conflict resolution styles than the general model (as measured by secure parent attachment).

Table 2

Regression coefficients for predictors of Conflict Resolution Styles $(N=134)$

\begin{tabular}{|c|c|c|c|c|c|c|c|c|}
\hline & $\begin{array}{c}\text { Positive } \\
\text { Problem } \\
\text { Solving }\end{array}$ & & $\begin{array}{c}\text { Conflict } \\
\text { Engage- } \\
\text { ment }\end{array}$ & & $\begin{array}{l}\text { With- } \\
\text { drawal }\end{array}$ & & $\begin{array}{l}\text { Com- } \\
\text { pliance }\end{array}$ & \\
\hline Order of Predictors & & $R^{2}$ & & $R^{2}$ & & $R^{2}$ & & $R^{2}$ \\
\hline Step 1 & & $.28 * * *$ & & $.17 * * *$ & & $.20 * * *$ & & $.13 * * *$ \\
\hline Gender & -.05 & & .08 & & .03 & & -.04 & \\
\hline Secure parental attachment & -.02 & & .02 & & -.07 & & $-.20 *$ & \\
\hline Secure partner attachment & $.52 * * *$ & & $-.41 * * *$ & & $.42 * * *$ & & $-.27 * *$ & \\
\hline Step 2 & & $.05^{*}$ & & .02 & & .01 & & .00 \\
\hline $\begin{array}{l}\text { Gender } x \text { secure parental } \\
\text { attachment }\end{array}$ & $-.27^{*}$ & & .27 & & -.12 & & -.09 & \\
\hline $\begin{array}{l}\text { Gender } x \text { secure partner } \\
\text { attachment }\end{array}$ & $.33^{*}$ & & -.17 & & -.03 & & -.04 & \\
\hline $\begin{array}{l}\text { Secure parental } \times \text { secure partner } \\
\text { attachment }\end{array}$ & .11 & & .01 & & -.09 & & .02 & \\
\hline Total $R^{2}$ & & $.33^{*}$ & & .20 & & .20 & & .14 \\
\hline Adjusted Total $R^{2}$ & & $.29 *$ & & .16 & & .17 & & .10 \\
\hline
\end{tabular}



Figure 1: The interaction of secure parental attachment on the positive problem solving style of men and women 




Figure 2: The interaction of secure partner attachment on the positive problem solving style of men and women

\section{Conflict beliefs}

The hierarchical regression analysis in Table 3 illustrates the extent to which secure parent and partner attachment, as well as gender and their interaction effects contribute to the conflict beliefs that arguing is threatening or beneficial. In terms of believing that arguing is beneficial, $24 \%$ of the variance in this variable was predicted by gender, secure parental and secure partner attachment, whilst the beta value of secure partner attachment ( $=.45)$ indicated that this was the stronger predictor.

Gender, secure parental attachment, and secure partner attachment together accounted for $49 \%$ of the variance in the belief that arguing is threatening at Step 1 . When examining the beta weights it becomes clear that secure partner attachment was again the significant predictor at Step $1(=-.68)$. The interaction effects (Step 2) between these variables explain another 3\% of the variance in the belief that arguing is threatening. With median splits of secure parental attachment and secure partner attachment (Figure 3) on the belief that arguing is threatening, the interaction effects become clearer: In terms of believing that arguing is threatening, individuals who had a high secure partner attachment (notwithstanding whether they had high or low secure parental attachment) were less likely to believe that arguing is threatening. However, for individuals who were currently not securely attached to their partner, a low secure parental attachment exacerbated their belief that arguing is threatening. In contrast, participants who had a high secure parental attachment were less likely to believe that arguing is threatening, even if they were currently less securely attached to their partner. This illustrates the protective function or buffering 
effect that having a secure parental attachment has on the current relationship, in particular on the belief that arguing is threatening.

Table 3

Regression coefficients for predictors of Conflict Beliefs $(N=134)$

\begin{tabular}{|c|c|c|c|c|}
\hline & $\begin{array}{l}\text { Arguing is } \\
\text { Threatening }\end{array}$ & & $\begin{array}{l}\text { Arguing is } \\
\text { Beneficial }\end{array}$ & \\
\hline Order of Predictors & & $R^{2}$ & & $R^{2}$ \\
\hline Step 1 & & $.49 * * *$ & & $.24 * * *$ \\
\hline Gender & -.02 & & -.12 & \\
\hline Secure parental attachment & -.07 & & .07 & \\
\hline Secure partner attachment & $-.68 * * *$ & & $.45 * * *$ & \\
\hline Step 2 & & $.03 *$ & & .01 \\
\hline $\begin{array}{l}\text { Gender } x \text { secure parental } \\
\text { attachment }\end{array}$ & .16 & & -.10 & \\
\hline $\begin{array}{l}\text { Gender } x \text { secure partner } \\
\text { attachment }\end{array}$ & -.20 & & .23 & \\
\hline $\begin{array}{l}\text { Secure parental } x \text { secure partner } \\
\text { attachment }\end{array}$ & $.16^{*}$ & & .01 & \\
\hline Total $R^{2}$ & & $.52 *$ & & .26 \\
\hline Adjusted Total $R^{2}$ & & $.50 *$ & & .22 \\
\hline
\end{tabular}

${ }^{*} \mathrm{p}<.05 ;{ }^{* *} \mathrm{p}<.01 ;{ }^{* * *} \mathrm{p}<.001$



Figure 3: The interaction of secure partner and secure parental attachment on the belief that arguing is threatening 


\section{Discussion}

Attachment styles are based on cognitive-affective schemas, or internal working models of attachment, and it greatly influences the way one interacts with and experiences one's world (Bowlby, 1973). Attachment theorists conceptualize that individuals simultaneously hold numerous mental models of attachment to attachment figures (e.g., Collins \& Read, 1994; Shaver, Collins, \& Clark, 1996). Collins and Read described a hierarchical attachment network with generalized attachment models featuring at the top of the hierarchy, and specific models featuring at lower levels. Bretherton and Munholland (1999) conceptualize generalized attachment as the adult's present mindset about the relationship with his/her primary caregivers, and this was also the conceptualization of global attachment in this study. They furthermore postulate that these internal working models give adults a system of rules that regulate affect, thoughts and behaviour in social interactions with attachment figures. Previously theorists (Collins \& Read; Crittenden, 1990), and researchers (e.g., Crowell \& Owens, 1996; Crowell et al., 2002) have indicated that specific attachment representations to relational partners develop in the context of various adult relationships.

Attachment theory suggests that working models are influenced by social development, and this includes a revision and integration of attachment based on new information and experiences (e.g., Hazan \& Shaver, 1987). In this manner an insecurely attached person can become increasingly secure by experiencing a relationship that disconfirms previous mental models, and vice versa (Hazan $\&$ Shaver, 1987). The stability of attachment models are thus heavily influenced by the consistency of the caregiving environment (Crowell et al., 2002). Previous findings (e.g., Owens et al., 1995; Pierce \& Lydon, 2001; Treboux et al., 2004) have indicated a weak to moderate correlation between secure parent and secure partner attachment, and this was also underscored by the current study's findings. These results indicate the link between globalized and partner-specific models (albeit limited in this context to secure attachment), and illustrate that these concepts are distinct, thus supporting more recent research which clearly distinguish between these concepts in attachment models (e.g., Cozzarelli et al., 2000).

Attachment theory posits that individuals with positive models of others will display communication styles exhibiting intimacy, whereas those with negative models of others will demonstrate communication behaviour reflecting avoidance and detachment. Since individuals create their social environments in ways that confirm their internal working models, attachment theory also predicts that attachment styles will reinforce these approach/avoidance behaviours (Bartholomew, 1993; Collins \& Read, 1994). In general, from the results presented above, it is clear that one's current partner-specific working 
models (rather than global model) have a significant influence on relationship specific outcomes, such as conflict resolution styles and conflict beliefs. Also, a secure attachment would imply that individuals experience themselves as worthy of love, they would also view others as trustworthy, approachable and responsive (Bartholomew \& Horowitz, 1991). Thus it came as no surprise that secure partner attachment (in particular) predicted the frequent use of positive problem solving, and the infrequent use of negative conflict behaviour.

These appraisal processes are specifically tied to the relational partner, and unique person-situation interactions and the findings from the current study are in line with previous research (e.g., Creasy, 2002; Cozzarelli et al., 2000; Pierce \& Lydon, 2001; Treboux et al., 2004). The current study found that in comparison to secure parental attachment, secure partner attachment more likely predicts conflict resolution behaviour (positive problem solving, withdrawal, conflict engagement and compliance), as well as conflict beliefs (arguing is threatening and arguing is beneficial). Two interaction effects also became evident from this study: Gender differences in positive problem solving became evident as a result of differential high/low secure parent and partner attachment; and the interaction between secure parental and partner attachment impacted on the belief that arguing is threatening.

In terms of secure parental attachment men with high secure parental attachment were found to be more likely than women with high secure parental attachment to display positive problem solving behaviour during conflict resolution. Thus, having a secure parental attachment acts as a larger buffer to displaying positive problem solving in the current relationship for men, than for women. Creasy (2002) previously found comparable levels of positive conflict behaviours between men and women in a sample of securely attached young adults. Attachment in Creasy's study however was measured by the Adult Attachment Interview which focused on measuring a number of childhood attachment experiences. Given that in the current study most of the participants identified their mother as their primary caregiver, it might be plausible that men associated their attachment experiences with their opposite-sex parent (mother) more closely with their current romantic relationship. As such, these secure parental attachment models are more predictive of positive conflict resolution behaviour in men, than in women. Other authors have suggested that individual responses will be influenced more by attachment models that are available at that time (e.g., Baldwin, Keelan, Fehr, Enns, \& Koh-Rangarajoo, 1996), and the results of the present study suggest that these general mental models are activated for men in particular with relation to conflict situations and positive conflict behaviour.

Both men and women had low positive problem solving scores when their secure parental attachment was low, although again, this was slightly more pronounced for men. These less secure parental attachment models will be associated with a greater difficulties in 
emotional regulation (Mickulincer et al, 2002), as well as greater fear of intimacy and abandonment (Le Poire et al., 1999), so it is expected that these individuals will be less able to utilize positive problem solving strategies (such as remain calm to listen, negotiate and compromise) in their current relationship.

In terms of secure partner attachment both men and women reported high positive problem solving behaviour when they were securely attached to their partners, and this is in line with previous research findings (Pistole, 1989; Koback \& Sceery, 1988). More broadly speaking this is also in line with findings which indicate that specific attachment models are more predictive of behavioural outcomes than general models (Cozzarelli et al., 2000). However, for the group of individuals who were less securely attached to their partners, women were less likely to report use of positive problem solving styles during conflict than men. For these women, conflict activated their less secure partner attachment models which in turn predicted their infrequent use of positive conflict behaviour. Previously Fichten and Wright in their study (1983) found that both satisfied and distressed wives engaged in more negative behaviours than husbands in their relationships, a finding which to some extent might support the current discrepancy between male and female positive problem solving behaviour, specifically for less secure partner attachment.

Researchers have found that insecure attachment is linked with irrational beliefs, such as 'arguing is threatening' (Campbell et al., 2005; Stackert \& Bursik, 2003). However, only in terms of the belief that arguing is threatening was an 'immunization effect' found to be present. These individuals with secure primary caregiver attachment were found to be less likely to believe that arguing is threatening, even though their current attachment to their partner might be less secure. This finding is in line with what Crowell et al. (2002) refer to as the stability of the secure base, which according to them once acquired is particularly difficult to unlearn or distort, even though a current insecure partner attachment might be present.

\section{Limitations}

The manner in which primary caregiver and partner attachments were measured are not indicative of actual primary caregiver or partner behaviour, but are representations of behaviour, which may or may not be similar to actual behaviour. Although attachment researchers believe that these representations are derived from actual behaviour, they are the individual's interpretations of behaviour and the connection has not been demonstrated in an empirical sense (Levy, Blatt, \& Shaver, 1998). Attachment representations are not accessible to direct observation, and self-report is one potential manner of measuring attachment representations. Also, scientifically, the self-reported survey data is more open to 
interpretation than experimental methodology, a problem common to attachment research (Waters, Crowell, Elliott, Corcoran, \& Treboux, 2002). It should therefore be noted that the current study's findings are correlational, and although there is an attempt to explain possible causes of self-reported behaviours and thoughts, it cannot be said with certainty that attachment styles cause these relationship-specific outcomes.

The current study only utilized secure parental and secure partner attachment as an overarching concept to distinguish between more and less secure individuals, but failed to include the subtleties of the underlying attachment styles, including anxious-ambivalent (or preoccupied) attachment, fearful attachment, dismissive attachment (Bartholomew \& Horowitz, 1991) and role reversed parental attachment (Le Poire et al., 1999). Future studies would do well to determine the manner in which these attachment styles in particular impact on relationship specific outcomes.

Attachment styles and other relationship variables, such as conflict resolution styles are relatively stable over time (e.g., Crowell et al., 2002), but new experiences could also potentially affect changes. The self-report questionnaires were administered once only, thus providing a snapshot view of current perspectives on attachments to partner and primary caregiver, as well as relationship satisfaction, conflict beliefs and conflict resolution styles. This did not allow for measurement of changes in these variables over time or for factors influencing changes longitudinally. The chosen methodology also does not account for dyadic interaction effects or the interplay of behaviours, which would inevitably shape relationships and relational outcomes. As a result of using an Internet survey no observation of the participants was possible, the setting was not controlled and there might have been some task misunderstanding effects (although none were reported). However, in comparing the findings from this study with results from previous studies (e.g., Cozzarelli et al., 2000; Creasy, 2002, Pistole, 1989) the results were mostly very similar. From this it is evident that Internet surveys are a legitimate, cost-effective and time efficient data-gathering method.

\section{Conclusion}

Findings from this study support the distinction between global and specific relational models (e.g., Cozzarelli et al., 2000; Pierce \& Lydon, 2001; Overall et al., 2003), specifically with regards to secure parental and secure partner attachment. In addition, the current study's findings that specific relational models are more closely tied to partnerspecific relational outcomes, also gives support to previous findings. In general it was found that secure partner attachment was more predictive of conflict resolution behaviour and conflict beliefs, than a global attachment model. However, it would appear that the global attachment model can be activated in the context of the current relationship under certain 
conditions (e.g., Baldwin et al., 1996). Thus, a gendered response to positive problem solving became evident. For example, for men a secure parental attachment is more likely to elicit positive problem solving behaviour during conflict, than for women. Women, however, who are not securely attached to their current romantic partners, will more infrequently use positive conflict strategies, than men. Neither does one model or another get activated or impact on the current relationship. For individuals who not only have a secure partner attachment, but also have a secure primary caregiver attachment, it becomes much more likely that they will believe that arguing is not threatening. In this manner there is one mental model compounding the effects of another mental model, pointing to the conceptual overlap between the global and specific mental models, but only with regards to some relationship variables. Similar to Treboux et al. (2004) however, it shows the closely intertwined nature of general and specific attachment as it impacts on an individual's current romantic relationship.

Although previous research has focused on some relationship specific outcomes, such as feelings of love and relationship satisfaction (e.g., Cozzarelli et al., 2000), future research would do well to focus on other relationship specific outcomes, specifically those that are relevant to individuals in distressed relationships. Replicating and examining these variables in an experimental context, that allows for greater control, would also add to the validity of these findings. Additional exploration of attachment configurations and its impact on relationship variables would contribute to empirical knowledge on the attachment process across the life-span, as well as clinical applications in the form of dealing with attachment-related issues in a therapeutic setting.

\section{References}

Aiken, L.S., \& West, S.G. (1991). Multiple regression: Testing and interpreting interactions. Newbury Park, CA: Sage.

Ainsworth, M.D.S., Blehar, M., Waters, E., \& Wall, S. (1978). Patterns of Attachment: A psychological study of the Strange Situation. Hillsdale, NJ: Erlbaum.

Baldwin, M.W., Keelan, M.P.R., Fehr, B., Enns, V., \& Koh-Rangarajoo, E. (1996). Socialcognitive conceptualizations of attachment working models: Availability and accessibility effects. Journal of Personality and Social Psychology, 71, 94-109.

Bartholomew, K. (1993). From childhood to adult relationships: Attachment theory and research. In S. Duck (Ed.), Understanding relationship processes: Learning about relationships (Vol. 2, pp. 30-62). Newbury Park, CA: Sage.

Bartholomew, K., \& Horowitz, L.M. (1991). Attachment styles among young adults: A test of a four-category model. Journal of Personality and Social Psychology, 61, 226-244. 
Bartholomew, K., \& Shaver, P.R. (1998). Methods of assessing adult attachment: Do they converge? In J.A. Simpson \& W.S. Rholes (Eds.), Attachment theory in close relationships (pp. 22-45). New York: Guilford Press.

Bippus, A.M., \& Rollin, E. (2003). Attachment style differences in relational maintenance and conflict behaviours: Friends' perceptions. Communication Reports 16, 113-124.

Bowlby, J. (1969). Attachment and loss: Vol. 1. Attachment. Reading, MA: Addison-Wesley.

Bowlby, J. (1973). Attachment and loss: Vol. 2. Separation, anxiety and anger. New York: Basic Books.

Bowlby, J. (1988). A secure base. London: Routledge.

Bretherton, I., \& Munholland, K. (1999). Internal working models in attachment relationships: A construct revisited. In J. Cassidy \& P. Shaver (Eds.), Handbook of attachment: Theory, research and clinical applications (pp. 89-111). New York: Guilford.

Campbell, L., Simpson, J.A., Boldry, J., \& Kashy, D.A. (2005). Perceptions of conflict and support in romantic relationships: The role of attachment anxiety. Journal of Personality and Social Psychology, 88, 510-531.

Collins, N.L., \& Read, S.J. (1994). Cognitive representations of attachment: The content and function of working models. In K. Bartholomew \& D. Perlman (Eds.), Advances in personal relationships (Vol. 5, pp. 53-90). London: Jessica Kingsley.

Cozzarelli, C., Hoekstra, S.J., \& Bylsma, W.H. (2000). General versus specific mental models of attachment: Are they associated with different outcomes? Personality and Social Psychology Bulletin, 26, 605-618.

Creasy, G. (2002). Associations between working models of attachment and conflict management behaviour in romantic couples. Journal of Counselling Psychology, 49(3), 365-375.

Crittenden, P.M. (1990). Internal representational models of attachment relationships. Infant Mental Health Journal, 11, 259-277.

Crowell, J.A., \& Owens, G. (1996). Current relationship interview and scoring system. Unpublished manuscript, State University of New York at Stony Brook.

Crowell, J.A., Treboux, D., \& Waters, E. (2002). Stability of attachment representations: The transition to marriage. Developmental Psychology, 38, 467-479.

Fichten, C.S., \& Wright, J. (1983). Problem-solving skills in happy and distressed couples: Effects of videotape and verbal feedback. Journal of Clinical Psychology, 39, 340-352

Fouladi, R.T. McCarthy, C.J., \& Moller, N.P. (2002). Paper-and-pencil or online: Evaluating mode effects on measures of emotional functioning and attachment. Assessment, 9(2), 204-215.

Gottman, J.M. (1994). What predicts divorce? The relationship between marital processes and marital outcomes. Hillsdale, NJ: Lawrence Erlbaum Associates. 
Gottman, J.M., \& Krokoff, L.J. (1989). Marital interaction and satisfaction: A longitudinal view. Journal of Consulting and Clinical Psychology, 57, 47-52.

Guerrero, L.K. (1996). Attachment style differences in intimacy and involvement: A test of the four-category model. Communication Monographs, 63, 269-292.

Hazan, C., \& Shaver, P.R. (1987). Romantic love conceptualized as an attachment process. Journal of Personality and Social Psychology, 52, 511-524.

Kiesler, S., \& Sproull, L.S. (1986). Response effects in an electronic survey. Public Opinion Quarterly, 50, 402-413.

Krantz, J.H., \& Dalal, R. (2000). Validity of web-based psychological research. In M.H. Birnbaum (Ed.), Psychological experiments on the Internet (pp. 35-60). San Diego, CA: Academic Press.

Kurdek, L.A. (1994). Conflict resolution styles in gay, lesbian, heterosexual nonparent, and heterosexual parent couples. Journal of Marriage and the Family, 56, 705-722.

Le Poire, B.A., Haynes, J., Driscoll, J., Driver, B.N., Wheelis, T.F., Hyde, M.K., et al. (1997). Attachment as a function of parental and partner approach-avoidance tendencies. Human Communication Research, 23, 413-441.

Le Poire, B.A., Shephard, C., \& Duggan, A. (1999). Nonverbal involvement, expressiveness, and pleasantness as predicted by parental and partner attachment style. Communication Monographs, 66, 293-311.

Levy, K.N., Blatt, S.J., \& Shaver, P.R. (1998). Attachment styles and parental representations. Journal of Personality and Social Psychology, 74, 407-419.

Mehta, R., \& Sivadas, E. (1995). Comparing response rates and response content in mail versus electronic mail surveys. Journal of Market Research Society, 37, 429-439.

Mikulincer, M., Gillath, O., \& Shaver, P.R. (2002). Activation of the attachment system in adulthood: Threat-related primes increase the accessibility of mental representations of attachment figures. Journal of Personality and Social Psychology, 83, 881-895.

Overall, N.C., Fletcher, G.J.O., \& Friesen, M.D. (2003). Mapping the intimate relationship mind: Comparison between three models of attachment representation. Personality and Social Psychology Bulletin, 29, 1479-1493.

Owens, G., Crowell, J. Pan, H. Treboux, D., O’Connor, E., \& Waters, E. (1995). The prototype hypothesis and the origins of attachment working models: Adult relationships with parents and romantic partners. In E. Waters, B. Vaughn, G. Posada, \& K. KondoIkemura (Eds.), Caregiving, cultural and cognitive models: New growing points of attachment theory and research, (pp. 216-233). Chicago: University of Chicago Press.

Paley, B., Cox, M.J., Burchinal, M.R., \& Payne, C.C. (1999). Attachment and marital functioning: Comparison of spouses with continuous-secure, earned-secure, 
dismissing, and preoccupied attachment stances. Journal of Family Psychology, 13, 580597.

Peden, B.F., \& Flashinski, D.P. (2004). Virtual research ethics: A content analysis of surveys and experiments online. In E.A. Buchanan, Readings in virtual research ethics: Issues and controversies (pp. 1-26). Hershey, PA: Information Science Publishing.

Pierce, T., \& Lydon, J.E. (2001). Global and specific relational models in the experience of social interactions. Journal of Personality and Social Psychology, 80, 613-631.

Pistole, M.C. (1989). Attachment in adult romantic relationships: Style of conflict resolution and relationship satisfaction. Journal of Social and Personal Relationships, 6, 505-510.

Pistole, M.C. \& Arricale, F. (2003). Understanding attachment: Beliefs about conflict. Journal of Counseling and Development, 81,318-329.

Simpson, J.A., \& Rholes, W.S. (1994). Stress and secure base relationships in adulthood. In K. Bartholomew \& D. Perlman (Eds.), Attachment processes in adulthood (pp.181-204). London: Jessica Kingsley.

Simpson, J.A., \& Rholes, S.W. (Eds.). (1998). Attachment theory and close relationships. New York: Guilford Press.

Shaver, P.R., Collins, N., \& Clark, C.L. (1996). Attachment styles and internal working models of self and relationship partners. In G.J.O. Fletcher \& J. Fitness (Eds.), Knowledge structures in close relationships: A social psychological approach (pp. 25-61). Mahwah, NJ: Lawrence Erlbaum.

Shi, L. (2003). The association between adult attachment styles and conflict resolution in romantic relationships. American Journal of Family Therapy, 31, 143-157.

Smith, M.A., \& Leigh, B. (1997). Virtual subjects: Using the Internet as an alternative source of subjects and research environment. Behaviour Research Methods, Instruments, హ Computers, 29, 496-505.

Stackert R.A., \& Bursik, K. (2003). Why am I unsatisfied? Adult attachment style, gendered irrational relationship beliefs, and young adult romantic relationship satisfaction. Personality and Individual Differences, 34,1419-1429.

Sümer, N., \& Cozzarelli, C. (2004). The impact of adult attachment on partner and self attributions and relationship quality. Personal Relationships, 11, 355-371.

Treboux, D., Crowell, J.A., \& Waters, E. (2004). When "New” meets “Old”: Configurations of adult attachment representations and their implications for marital functioning. Developmental Psychology, 40, 295-314.

Wampler, K.S., Shi, L., Nelson, B.S., \& Kimball, T.G. (2003). The Adult Attachment Interview and observed couple interaction: Implications for an intergenerational perspective on couple therapy. Family Process, 42, 497-515. 
Waters, E., Crowell, J., Elliott, M., Corcoran, D., \& Treboux, D. (2002). Bowlby's secure base theory and social/personality psychology of attachment: Work(s) in progress. Attachment \& Human Development, 4, 230-242.

Received: $31 / 10 / 2006$

Accepted: 17/05/2007 